\title{
(2) OPEN ACCESS \\ Cost-effectiveness of full endoscopic versus open discectomy for sciatica
}

\author{
Pravesh Shankar Gadjradj @ (1, ${ }^{1,2}$ Hana M Broulikova, ${ }^{3}$ Johanna M van Dongen, ${ }^{3}$ \\ Sidney M Rubinstein, ${ }_{1}^{4}$ Paul R Depauw ${ }_{1}^{5}$ Carmen Vleggeert, ${ }_{1}^{6}$ Ankie Seiger, ${ }_{1}^{4}$ \\ Wilco C Peul, ${ }^{6}$ Job L van Susante, ${ }^{7}$ Maurits W van Tulder, ${ }^{4,8}$ Biswadjiet S Harhangi ${ }^{2}$
}

\begin{abstract}
- Additional supplemental material is published online only. To view, please visit the journal online (http://dx.doi. org/10.1136/bjsports-2021104808)
\end{abstract}

For numbered affiliations see end of article.

Correspondence to Dr Biswadjiet S Harhangi, Department of Neurosurgery, Erasmus MC, Rotterdam, ZuidHolland, Netherlands; b.s.harhangi@erasmusmc.nl

North American Spine Society meeting 2021, Boston, MA U.S.A.

Accepted 19 October 202

\section{Check for updates}

(C) Author(s) (or their employer(s)) 2022. Re-use permitted under CC BY-NC. No commercial re-use. See rights and permissions. Published by BMJ.

To cite: Gadjradj PS, Broulikova HM, van Dongen JM, et al. Br I Sports Med Epub ahead of print: [please include Day Month Year]. doi:10.1136/ bjsports-2021-104808

\section{ABSTRACT}

Objective To assess the costs and cost-effectiveness of percutaneous transforaminal endoscopic discectomy (PTED) compared with open microdiscectomy among patients with sciatica.

Methods This economic evaluation was conducted alongside a 12-month multicentre randomised controlled trial with a non-inferiority design, in which patients were randomised to PTED or open microdiscectomy. Patients were aged from 18 to 70 years and had at least 6 weeks of radiating leg pain caused by lumbar disc herniation. Effect measures included leg pain and quality-adjusted life years (QALYs), as derived using the EQ-5D-5L. Costs were measured from a societal perspective. Missing data were multiply imputed, bootstrapping was used to estimate statistical uncertainty, and various sensitivity analyses were conducted to determine the robustness. Results Of the 613 patients enrolled, 304 were randomised to PTED and 309 to open microdiscectomy. Statistically significant differences in leg pain and QALYS were found in favour of PTED at 12 months follow-up (leg pain: 6.9; 95\% Cl 1.3 to 12.6 ; QALYs: $0.040 ; 95 \% \mathrm{Cl}$ 0.007 to 0.074$)$. Surgery costs were higher for PTED than for open microdiscectomy (ie, €4500/patient vs $€ 4095 /$ patient). All other disaggregate costs as well as total societal costs were lower for PTED than for open microdiscectomy. Cost-effectiveness acceptability curves indicated that the probability of PTED being less costly and more effective (ie, dominant) compared with open microdiscectomy was $99.4 \%$ for leg pain and $99.2 \%$ for QALYS.

Conclusions Our results suggest that PTED is more cost-effective from the societal perspective compared with open microdiscectomy for patients with sciatica. Trial registration number NCT02602093.

\section{INTRODUCTION}

As sciatica has a lifetime prevalence of up to $43 \%$ in the general population, it has a high disease burden at the individual patient level as well as at the societal level. ${ }^{1}$ At the individual level, patients can suffer from leg pain which can be accompanied by sensory or motor loss, possibly leading to disability and a poor health-related quality of life. ${ }^{23}$ As so, sciatica can severely impact the lives of active adults, especially as sciatica mostly affects individuals aged between 30 and 50 years. ${ }^{2}$ At societal level, sciatica comes with a major financial burden mainly because of sick leave and hospital costs. ${ }^{5}$

Fortunately, the natural course of sciatica is favourable as majority of the cases resolve with conservative treatment. ${ }^{6}$ Due to the high prevalence of sciatica, however, surgery for lumbar disc herniation is a frequently performed procedure. $^{78}$ The current standard surgical procedure for the treatment of lumbar disc herniation is open microdiscectomy. ${ }^{7910}$ Percutaneous transforaminal endoscopic discectomy (PTED) was introduced as a less invasive alternative. ${ }^{11} 12$ In contrast to open microdiscectomy, PTED is performed under local anaesthesia and is offered as outpatient surgery. ${ }^{13}$ Furthermore, PTED is performed from a far lateral approach and requires surgeons to operate from a two-dimensional view, which makes performing PTED more challenging even for experienced surgeons. Because of this challenging learning curve, the unclear merits of PTED over conventional microdiscectomy and possible issues associated with reimbursement, PTED is offered by only a few surgeons worldwide. ${ }^{714}$

Previous research has compared various outcomes between PTED and open microdiscectomy and suggested no differences between both procedures for leg pain and functional status. ${ }^{15-17}$ PTED, however, was found to have the advantage of less intraoperative blood loss and shorter hospital stays compared with open microdiscectomy. Some prior research has examined the direct costs of both procedures. ${ }^{18} 19$ One study assessed the costs of the operating theatre, hospitalisation, endoscopes and sterilisation of the surgical equipment and found significantly higher costs for PTED than for open microdiscectomy. ${ }^{19}$ Among these costs, endoscopes were identified to be the biggest cost driver and made up $66 \%$ of the costs of PTED. The other study found the cost of hospitalisation to be significantly lower for PTED by $27 \%$ compared with open microdiscectomy. ${ }^{18}$ No studies performed a large, full trial-based economic evaluation, in which both the costs and effects of PTED and open microdiscectomy were assessed and compared with one another.

The PTED-study aimed to assess the effectiveness and cost-effectiveness (CE) of PTED compared with open microdiscectomy in patients with lumbar disc herniation. ${ }^{20}$ Results of the effectiveness analyses suggest that PTED is non-inferior to open microdiscectomy in leg pain reduction at 12 months after surgery. ${ }^{21}$ Furthermore, PTED had more favourable results for patient-reported leg pain and health-related quality of life as compared with open microdiscectomy. It is unknown, however, how the difference in costs between both procedures is related to the corresponding differences 
in leg pain and health-related quality of life. Furthermore, as PTED is not covered by all insurance providers, an economic evaluation comparing PTED with open microdiscectomy is warranted. Therefore, this study aimed to explore the CE of PTED compared with open microdiscectomy among patients with lumbar disc herniation from a societal perspective at 12 months after surgery. Among others, a sensitivity analysis was performed from the healthcare perspective to assess whether the results are robust to the adoption of the healthcare perspective and to inform decision-makers from countries where the healthcare perspective is recommended (eg, the UK and Belgium).

\section{METHODS}

\section{Patients and setting}

This economic evaluation was conducted alongside the PTEDstudy, a large multicentre randomised controlled trial with a non-inferiority design.

A detailed description of the PTED-study, including its sample size calculation, has previously been published. ${ }^{20}$ In brief, participants were recruited between February 2016 and April 2019 from three hospitals and one private health clinic in the Netherlands. To be eligible, patients had to meet the following inclusion criteria: age between 18 and 70 years; $>10$ weeks of radiating pain with or without motor or sensory loss in the leg or with $>6$ weeks of excessive radiating pain and no tendency for any clinical improvement; indication for surgery; MRI-confirmed lumbar disc herniation with nerve compression with or without concomitant spinal or lateral recess stenosis; sufficient knowledge of the Dutch language. Exclusion criteria were previous surgery on the same or adjacent disc level; cauda equina syndrome; spondylitis or degenerative spondylolisthesis; pregnancy; severe comorbid medical or psychiatric disorder (American Society of Anesthesiologists $>2$ ); severe caudal or cranial sequestration; contraindication for surgery; moving abroad at short notice. Patients with lumbar disc herniation were screened for eligibility during their outpatient consultation by one of the participating surgeons. Eligible patients received written information about the study and were given at least 2 days to consider participation. After that period, a trained research nurse further screened patients who were willing to participate, informed consent was obtained, and baseline measurements were performed. Then, patients were randomised in a 1:1 ratio to PTED or OM, using a computergenerated, random-number tables with variable block sizes (ie, $4,6,8)$, stratified by treatment centre. Treatment allocation was concealed and was performed by an independent research nurse. Blinding of patients was not possible due to the fundamentally different nature of both procedures. Outcome assessors were not blinded either, because all outcomes were self-reported. ${ }^{20}$

\section{Interventions}

The PTED procedure has been extensively described elsewhere. ${ }^{11}$ In brief, PTED was performed under local anaesthesia and conscious sedation, on an outpatient basis. By means of fluoroscopy and a guidewire, conical rods were introduced into the neuroforamen. Subsequently, drills were introduced to enlarge the neuroforamen, followed by an endoscope and rongeur to remove the disc fragments.

Open microdiscectomy was performed under general anaesthesia. The use of a microscope or surgical loupes was optional. A paramedian incision was made. Following the identification of the lamina, the yellow ligament was removed to identify the nerve root and disc herniation. Laminotomy, as well as foraminotomy, was performed, if necessary. For the foraminal herniated disc, a partial medial facetectomy was used, and for the extraforaminal herniated disc, an approach alongside the facet joints was used. The patient was discharged as soon as medically responsible, which is usually 1 day after surgery.

\section{Cointerventions}

Pain medication was offered to patients, if deemed necessary. Use of cointerventions was monitored using self-reported resource use questionnaires.

\section{Learning curve}

Prior to this study, only two surgeons in the Netherlands were proficient in PTED. During this study, one of these surgeons provided PTED training to the other participating surgeons, all of whom had between 8 and 11 years of surgical experience. It was expected that about 50 patients per surgeon were needed for them to become proficient in PTED (ie, 'learning curve'). These patients were registered as learning curve patients and were excluded from the primary analysis. ${ }^{20}$

\section{Effect measures}

The primary effect measures for the economic evaluation were intensity of leg pain measured on the Visual Analogue Scale (VAS) ranging from 0 (no pain) to 100 (worst imaginable pain) and quality-adjusted life years (QALYs), derived from the EQ-5D-5L. ${ }^{20}$ QALYs, a commonly used outcome in economic evaluation, are a generic measure which provides a common outcome metric across clinical areas enabling comparisons across conditions. We also included pain intensity because it was the primary clinical outcome of the effectiveness trial and facilitates comparison of the results within the Spine-field. Both measures were assessed at baseline, the day after surgery, at 2, 4 and 6 weeks, and 3, 6, 9, 12 months. The EQ-5D-5L measures healthrelated quality of life in five health dimensions: mobility, selfcare, daily activities, pain/ discomfort and anxiety/depression. The Dutch EQ-5D-5L tariff was used to convert the patients' EQ-5D-5L health states into utility scores, anchored by the health states of death (0) and perfect health (1.00). ${ }^{22}$ QALYs were estimated using the 'area under the curve', meaning that QALYs were calculated by multiplying the patients' health state utility scores with the time spent in that health state. A linear relationship between the patients health state utility scores at the various time points was assumed. ${ }^{23}$ The total QALY of the 1-year follow-up period was calculated by adding up the QALYs for each follow-up period (0-2 weeks, 2-4 weeks, 4-6 weeks, etc) assuming a linear increase in QALY within each period.

\section{Cost measures}

Resource use was assessed using cost questionnaires administered at baseline and at 2, 4 and 6 weeks, and 3, 6, 9, 12 months. Since this study adopted a social perspective, both direct and indirect costs were included. Direct costs included costs of the intervention, primary healthcare use, secondary healthcare use and the use of medication. Intervention costs were estimated using hospital accounting records, while all other healthcare utilisation was valued according to the Dutch guidelines ${ }^{24}$ and medication use using prices of the Dutch Health Care Institute (http://medicijnkosten.nl). Costs of the interventions include the time of the operating room used, the costs of the medications used during the surgery and for open microdiscectomy also the cost for one overnight hospital stay. Indirect costs consisted of absenteeism, presenteeism, unpaid productivity and informal care costs. Absenteeism was assessed by asking patients to report 
their number of sick days and valuing them using the friction cost method (friction period $=12$ weeks) with wages adjusted for gender. ${ }^{24}$ Presenteeism (ie, reduced productivity at work) was assessed using the World Health Organization-Health and Work Performance Questionnaire and valued using the same genderspecific wages. Unpaid productivity losses (ie, losses due to being unable to perform unpaid activities, such as volunteer work) and informal care (ie, care by family and friends) were valued using a recommended Dutch shadow price $(€ 15)$. All costs were converted to euros 2019 using consumer price indices. Discounting of costs was not necessary.

\section{Confounding variables}

Based on the literature, ${ }^{25}$ clinical experience and consensus among the project team, the following potential confounders were identified: age (years), gender (male/female), smoking status (yes/no), body mass index (weight/height, ${ }^{2}$ employment status (yes/no), duration of complaints (months), morphological location of disc herniation (intraforaminal/extraforaminal), psychopathology as measured with the Four-Dimensional Symptom Questionnaire, ${ }^{26}$ and treatment preferences (no/PTED/open microdiscectomy).

\section{Statistical analyses}

A CE analysis (CEA) and a cost-utility analysis (CUA) were conducted. In the CEA, total costs were related to improvement of leg pain during 12-month follow-up. In the CUA, total costs were related to QALYs gained during follow-up. The primary analysis was conducted according to the intention-totreat approach. All missing data were imputed using multivariate imputation by chained equations. ${ }^{27}$ The imputation was stratified by treatment group to account for association of the treatment group with missingness. ${ }^{28}$ To deal with the association between being part of the learning curve group (yes/no) and the missingness of data, data from learning curve patients were excluded before imputing data for the main analysis and five sensitivity analyses. Predictive mean matching was used to create ten complete datasets. Disaggregate cost differences were analysed using linear regression models, both adjusted and unadjusted for confounders. Differences in total costs and effects between treatment groups were obtained from a system of seemingly unrelated regressions that accounted for the potential correlation between costs and effects. ${ }^{29}$ These total cost and effect differences were adjusted for baseline and confounders. Incremental cost-effectiveness ratios (ICERs) were calculated by dividing incremental costs by incremental effects. Uncertainty surrounding ICERs and cost differences were estimated by bias corrected and accelerated bootstrapping with 5000 repetitions. Uncertainty was presented using CE Planes and cost-effectiveness acceptability curves (CEACs). ${ }^{30} 31$ Results were pooled over the imputed datasets using Rubin's rules. ${ }^{27}$ Analyses were performed in R statistical programming language, V.3.6.1.

\section{Sensitivity analyses}

To assess the robustness of the results, six sensitivity analyses were performed for both effect measures. First, a crude analysis was run (unadjusted for potential confounders). Second, only complete cases were used. Third, two scenarios of PTED intervention costs were considered. In the high-cost scenario, the cost of PTED was $€ 5000 /$ patient, that is, $€ 500$ more than in the main analysis. In the low-cost scenario, the cost of PTED and open microdiscectomy were equal, that is, €4095/patient. Fourth, productivity losses were measured according to the human capital approach. Fifth, the healthcare perspective was adopted. Sixth, learning curve patients were included. Except for the high-cost and low-cost scenari's, all sensitivity analyses were planned a priori.

\section{Patient involvement}

Prior to the start of the PTED-study, the proposed study design and study procedures were presented to the relevant physician organisations, members of the Dutch Health Insurance board and members of the patient organisation 'de Wervelkolom' (translated: the Spine). Based on the input of these organisations on aspects such as feasibility, patient friendliness and patient safety, the study design would be updated if necessary. Furthermore, the organisations such as the patient organisation were invited to be part of the half-yearly board meetings during which recruitment, implementation and results of the study were discussed.

\section{RESULTS}

\section{Patients}

Between February 2016 and April 2019, 711 patients were assessed for eligibility. Of them, 613 met the inclusion criteria and agreed to participate. The trial was finalised before reaching the estimated sample size of 682 participants, because the inclusion term of the study was reached. These patients were randomised to PTED $(n=304)$ or open microdiscectomy $(n=309)$. In the PTED group, 125 patients were considered learning curve patients and were excluded from the primary analysis. The final study sample counted 488 patients and consisted of 179 and 309 patients in the PTED and open microdiscectomy group, respectively. Patient characteristics were similar in both groups (table 1). All follow-up questionnaires were completed by 313 patients, whereas 49 patients in the PTED group and 126 in the open microdiscectomy group missed at least one questionnaire. In total, $16 \%$ of follow-up data was missing (figure 1). Participants with complete and incomplete data differed in terms of gender, employment status, treatment preference, depression, anxiety, duration of symptoms, probability of second surgery and baseline utility. All of these variables were included in the imputation model.

\section{Clinical outcomes}

Statistically significant differences in leg pain and QALYs were found (table 3). In comparison to the open microdiscectomy group, patients in the PTED group experienced a 6.9 larger VAS score reduction in leg pain $(95 \% \mathrm{CI} 1.3$ to 12.6$)$ and gained 0.040 QALYs (95\% CI 0.007 to 0.074 ) at 12 months follow-up. Of the patients in the PTED-group $94.2 \%$ could be discharged on the day of surgery compared with $5.6 \%$ in the open microdiscectomy group. The rate of repeated surgery within 1 year was $5.3 \%$ in the PTED group vs $5.6 \%$ in the open microdiscectomy group.

\section{Costs}

Surgery costs were higher for PTED than for open microdiscectomy, that is, €4500/patient vs €4095/patient. All other disaggregate costs were lower for PTED than for open microdiscectomy. The differences in primary healthcare, informal care, absenteeism and presenteeism costs were statistically significant. Total societal costs were significantly lower for PTED than for open microdiscectomy by $€ 2787$ (95\% CI -4401 to -1181 ). Total healthcare costs were lower for PTED than for open microdiscectomy as well, but the difference was not statistically significant. Presenteeism and absenteeism were the biggest cost drivers (table 2). 
Original research

Table 1 Baseline characteristics of included patients

\begin{tabular}{|c|c|c|}
\hline Characteristic & $\begin{array}{l}\text { PTED } \\
(\mathrm{N}=179)\end{array}$ & $\begin{array}{l}\text { OM } \\
(\mathrm{N}=309)\end{array}$ \\
\hline Age-year (SD) & $45.3 \pm 12.4$ & $45.7 \pm 11.3$ \\
\hline Male sex-no (\%) & $99(55.3)$ & $180(58.3)$ \\
\hline Current smoker-no (\%) & $43(24.0)$ & $91(29.5)$ \\
\hline Body mass index- $-\mathrm{kg} / \mathrm{m}^{2}$ & $26.6 \pm 4.1$ & $26.8 \pm 5.4$ \\
\hline Paid employment-no (\%) & $151(84.4)$ & $242(78.6)$ \\
\hline Duration of sciatica-months & $4.2 \pm 3.0$ & $4.2 \pm 2.9$ \\
\hline Radiating pain in the right leg一no (\%) & $84(46.9)$ & $155(50.2)$ \\
\hline Sensory disturbances-no (\%) & $161(89.9)$ & $290(93.3)$ \\
\hline Muscle weakness-no (\%) & $92(51.4)$ & $183(59.2)$ \\
\hline Difference in deep-tendon reflexes in the knees-no (\%) & $48(26.8)$ & $81(26.4)$ \\
\hline Difference in deep-tendon reflexes in the ankles-no (\%) & $42(23.5)$ & $77(25.1)$ \\
\hline \multicolumn{3}{|l|}{ Level of disc herniation causing sciatica-no (\%) } \\
\hline L2-L3 & $2(1.1)$ & $7(2.3)$ \\
\hline L3-L4 & $15(8.4)$ & $13(4.2)$ \\
\hline L4-L5 & $68(38.0)$ & $137(44.3)$ \\
\hline L5-L6 & $1(0.6)$ & $2(0.6)$ \\
\hline L5-S1 & $93(52.0)$ & $148(47.9)$ \\
\hline L6-S1 & 0 & $2(0.6)$ \\
\hline \multicolumn{3}{|l|}{ Score on the Visual Analogue Scale of pain* } \\
\hline Leg pain & $67.3 \pm 21.7$ & $69.9 \pm 20.6$ \\
\hline Back pain & $48.7 \pm 27.6$ & $45.4 \pm 29.7$ \\
\hline Oswestry Disability Index† & $44.5 \pm 16.9$ & $45.5 \pm 17.1$ \\
\hline Score on the Visual Analogue Scale of quality of life $\neq$ & $46.8 \pm 19.9$ & $48.8 \pm 21.9$ \\
\hline \multicolumn{3}{|l|}{ SF-36 score§ } \\
\hline Physical component summary & $30.4 \pm 7.7$ & $29.6 \pm 7.7$ \\
\hline Mental component summary & $47.4 \pm 10.8$ & $46.5 \pm 11.3$ \\
\hline \multicolumn{3}{|l|}{ Four-dimensional symptom questionnaireף } \\
\hline Distress & $9.7 \pm 7.2$ & $9.3 \pm 7.4$ \\
\hline Depression & $1.0 \pm 1.9$ & $1.1 \pm 2.2$ \\
\hline Anxiety & $1.3 \pm 2.4$ & $1.5 \pm 2.7$ \\
\hline Somatisation & $6.8 \pm 4.3$ & $7.2 \pm 5.1$ \\
\hline Preference for PTED—no (\%) & 85.5 & 77.9 \\
\hline
\end{tabular}

One patient in the open microdiscectomy group had missing scores on the Oswestry Disability Index, VAS for QoL and back pain, Four-dimensional symptom questionnaire and

Short-Form-36 at baseline. Values are means \pm SD.

* The visual-analogue scale scores the intensity of leg and back pain from 0 to 100 with higher scores indicating more pain.

†The Oswestry Disability Index measures functional disability from 0 to 100 with higher scores indicating more functional disability.

$¥$ The visual-analogue scale of quality of life scores the general quality of life from 0 to 100 with higher scores indicating a better quality of life.

$\S$ The SF-36 score can be summarized in a physical component summary and a mental component summary using normative data. Higher scores indicate a better quality of life.

१The four-dimensional symptom questionnaire measures distress in four categories.

PTED, percutaneous transforaminal endoscopic discectomy; QoL, quality of life; VAS, Visual Analogue Scale.

\section{Cost-effectiveness}

At 12 months, PTED was found to be a cost-effective and even a dominant treatment strategy over open microdiscectomy for leg pain and QALYs, that is, PTED was on average both less costly and more effective than open microdiscectomy (table 3). CE planes show that the probability of PTED being dominant over open microdiscectomy in about $99.4 \%$ for leg pain and $99.2 \%$ for QALYs (ie, the proportion of pairs located in the south-east quadrant; figure 2A,C). In line with these findings, both CEACs show that the probability of PTED being cost-effective compared with open microdiscectomy was $99.4 \%$ for leg pain and $99.2 \%$ for QALYs, for all willingness-to-pay thresholds (figure 2B,D).

\section{Sensitivity analyses}

In all six sensitivity analyses (table 3 and online supplemental figure 1), PTED was found a cost-effective and oftentimes even a dominant treatment strategy, compared with open microdiscectomy for both leg pain and QALYs. The dominance was least profound when the healthcare perspective was adopted in which no productivity losses were considered. In this sensitivity analysis, however, the probability of PTED being costeffective compared with open microdiscectomy remained high at reasonable values of willingness to pay for both outcomes.

\section{DISCUSSION}

\section{Key findings}

Results of this study suggest that PTED is cost-effective compared with open microdiscectomy for patients with a lumbar disc herniation from the societal perspective within the first year of surgery. That is, PTED was found to be dominant (ie, more effective and less costly) compared with open microdiscectomy for leg pain and QALYs. CE planes indicated that the probability of PTED being dominant over open microdiscectomy was 


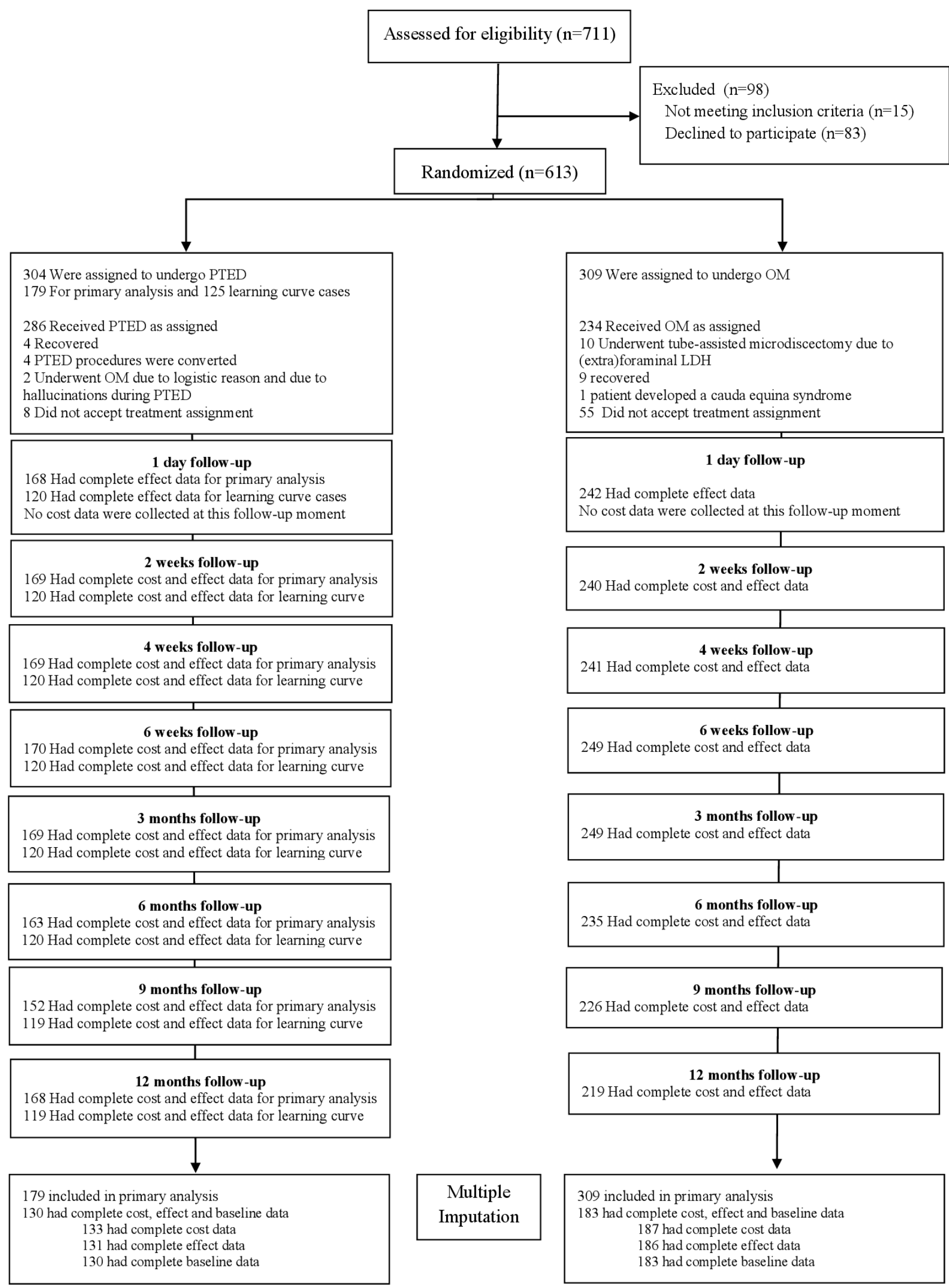

Figure 1 Flow chart of study procedures and measurements. PTED, percutaneous transforaminal endoscopic discectomy. 


\section{Original research}

Table 2 Mean cost (in euros) per patient receiving PTED and open microdiscectomy and mean cost differences between groups during follow-up

\begin{tabular}{|c|c|c|c|c|}
\hline Cost category & PTED $n=179$, mean (SEM) & OM n=309, mean (SEM) & Cost difference, crude mean $(95 \% \mathrm{Cl})$ & Cost difference, adjusted mean $(95 \% \mathrm{Cl})$ \\
\hline \multicolumn{5}{|l|}{ Direct costs } \\
\hline Surgery & 4500 & 4095 & 405 & 405 \\
\hline Primary care & $632(77)$ & $918(78)$ & $-287(-476$ to -67$)$ & $-307(-497$ to -102$)$ \\
\hline Secondary care & $725(186)$ & $1061(222)$ & $-336(-948$ to 140$)$ & -245 (-773 to 243$)$ \\
\hline Medication & $8(2)$ & $38(23)$ & $-30(-93$ to -11$)$ & $-11(-26$ to 0$)$ \\
\hline \multicolumn{5}{|l|}{ Indirect costs } \\
\hline Informal care & $172(43)$ & $334(63)$ & $-162(-306$ to -28$)$ & $-152(-283$ to -18$)$ \\
\hline Absenteeism & 4774 (389) & $5820(361)$ & $-1047(-2050$ to -14$)$ & $-924(-1808$ to -37$)$ \\
\hline Presenteeism & $3183(396)$ & $3738(435)$ & $-555(-1629$ to 503$)$ & $-1007(-1757$ to -313$)$ \\
\hline Unpaid productivity loss & $1097(220)$ & $1629(180)$ & $-532(-1019$ to 65$)$ & $-518(-1011$ to 61$)$ \\
\hline Total healthcare costs & $5865(215)$ & $6112(248)$ & $-248(-901$ to 316$)$ & $-138(-711$ to 415$)$ \\
\hline Total societal costs & $15090(719)$ & $17633(700)$ & $-2543(-4380$ to -686$)$ & $-2787(-4401$ to -1181$)$ \\
\hline
\end{tabular}

Please note that the difference in total societal costs of this table slightly differs from that of table 3 . This is given by the fact that in the current table, linear regression was used for estimating cost differences, whereas for table 3 a system of Seemingly Unrelated Regressions was used.

Total values are depicted in bold font.

PTED, percutaneous transforaminal endoscopic discectomy; SEM, standard error of the mean.

99.4\% for leg pain and 99.2\% for QALYs. Sensitivity analyses confirmed the results were robust to the handling of measured confounding, the applied method for handling missing data, the unit price of PTED, the applied method for valuing productivity losses, and the applied perspective.

\section{Comparison with other studies}

Other randomised controlled trials assessing the CE of PTED compared with open microdiscectomy, or another surgical technique for patients with lumbar disc herniation, are lacking. A recent non-randomised study assessed the CE of open microdiscectomy compared with three different endoscopic techniques, one of which was PTED. ${ }^{32}$ They showed that both (direct and indirect) costs and QALYs gained were in favour of endoscopic surgery, which is in line with our findings. The previous study, however, was limited by its non-randomised and retrospective design and was conducted from a healthcare perspective only.

\section{Strengths and limitations}

Strengths of this study are its high response rate, its large sample size, its design as a randomised controlled trial, and its low number of missing values and lost to follow-up. Moreover, a wide range of sensitivity analyses was performed to determine the robustness of the results. All these attributes support the validity of the findings observed in this study. We also consider it a strength that a covenant was signed prior to commencement

Table 3 Differences in pooled mean costs and effects ( $95 \%$ Cls), incremental cost-effectiveness (CE) ratios, and the distribution of incremental cost-effect pairs around the quadrants of the cost-effectiveness planes for PTED compared with usual care

\begin{tabular}{|c|c|c|c|c|c|c|c|c|c|c|}
\hline & \multicolumn{2}{|c|}{ Sample size } & \multirow{2}{*}{ Outcome measure } & \multirow{2}{*}{$\frac{\Delta \mathrm{C}(95 \% \mathrm{Cl})}{€}$} & \multirow{2}{*}{$\begin{array}{l}\Delta \mathrm{e}(95 \% \mathrm{Cl}) \\
\text { Points }\end{array}$} & \multirow{2}{*}{$\begin{array}{l}\text { ICER } \\
\text { €/point }\end{array}$} & \multicolumn{4}{|c|}{ Distribution CE-plane (\%) } \\
\hline & PTED & $\mathrm{OM}$ & & & & & NE & SE & SW & NW \\
\hline \multirow[t]{2}{*}{$\begin{array}{l}\text { Main analysis- } \\
\text { imputed dataset }\end{array}$} & 179 & 309 & $\begin{array}{l}\text { Leg pain (range: } 0-100 \text {, lower } \\
\text { is better) }\end{array}$ & $-2786(-4399$ to -1181$)$ & $6.9^{*}(1.3$ to 12.6$)$ & -402 Dominant & 0.1 & 99.4 & 0.5 & 0 \\
\hline & 179 & 309 & QALYs (range: 0-1) & $-2825(-4400$ to -1222$)$ & 0.040 (0.007 to 0.074$)$ & -70235 Dominant & 0.1 & 99.2 & 0.7 & 0 \\
\hline \multirow[t]{2}{*}{$\begin{array}{l}\text { SA1—unadjusted } \\
\text { outcomes }\end{array}$} & 179 & 309 & $\begin{array}{l}\text { Leg pain (range: } 0-100 \text {, lower } \\
\text { is better) }\end{array}$ & $-2543(-4380$ to -686$)$ & $8.2^{*}(2.5$ to 13.9$)$ & -310 Dominant & 0.6 & 99.2 & 0.1 & 0 \\
\hline & 179 & 309 & QALYs (range: $0-1$ ) & $-2543(-4380$ to -686$)$ & 0.052 (0.016 to 0.088 ) & -48496 Dominant & 0.6 & 99.2 & 0.2 & 0 \\
\hline \multirow[t]{2}{*}{ SA2 - complete cases $\dagger$} & 130 & 183 & $\begin{array}{l}\text { Leg pain (range: } 0-100 \text {, lower } \\
\text { is better) }\end{array}$ & $-2083(-3991$ to -234$)$ & $7.8^{*}(1.5$ to 14.0$)$ & -267 Dominant & 1.5 & 98 & 0.5 & 0 \\
\hline & 130 & 183 & QALYs (range: 0-1) & $-2133(-4029$ to -280$)$ & $0.031(-0.008$ to 0.070$)$ & -68014 Dominant & 1 & 93.3 & 5.4 & 0.3 \\
\hline \multirow[t]{2}{*}{$\begin{array}{l}\text { SA3a-cost of } \\
\text { PTED }=5000\end{array}$} & 179 & 309 & $\begin{array}{l}\text { Leg pain (range: } 0-100 \text {, lower } \\
\text { is better) }\end{array}$ & $-2260(-3876$ to -650$)$ & $6.9^{*}(1.3$ to 12.6$)$ & -326 Dominant & 0.6 & 98.9 & 0.5 & 0 \\
\hline & 179 & 309 & QALYs (range: 0-1) & $-2300(-3916$ to -693$)$ & 0.040 (0.007 to 0.074$)$ & -57167 Dominant & 0.5 & 98.8 & 0.7 & 0 \\
\hline \multirow[t]{2}{*}{$\begin{array}{l}\text { SA3b-cost of } \\
\text { PTED=Cost of OM }\end{array}$} & 179 & 309 & $\begin{array}{l}\text { Leg pain (range: } 0-100 \text {, lower } \\
\text { is better) }\end{array}$ & $-3212(-4824$ to -1610$)$ & $6.9 *(1.3$ to 12.6$)$ & -464 Dominant & 0 & 99.5 & 0.5 & 0 \\
\hline & 179 & 309 & QALYs (range: $0-1$ ) & $-3251(-4863$ to -1651$)$ & 0.040 (0.007 to 0.074$)$ & -80820 Dominant & 0 & 99.3 & 0.7 & 0 \\
\hline \multirow[t]{2}{*}{$\begin{array}{l}\text { SA4-human capital } \\
\text { approach }\end{array}$} & 179 & 309 & $\begin{array}{l}\text { Leg pain (range: } 0-100 \text {, lower } \\
\text { is better) }\end{array}$ & $-4111(-6384$ to -1919$)$ & $6.9^{*}(1.3$ to 12.5$)$ & -594 Dominant & 0 & 99.5 & 0.5 & 0 \\
\hline & 179 & 309 & QALYs (range: $0-1$ ) & -4179 (-6466 to -1983$)$ & 0.040 (0.007 to 0.074$)$ & -103256 Dominant & 0 & 99.3 & 0.7 & 0 \\
\hline \multirow[t]{2}{*}{$\begin{array}{l}\text { SA5-healthcare } \\
\text { perspective }\end{array}$} & 179 & 309 & $\begin{array}{l}\text { Leg pain (range: } 0-100 \text {, lower } \\
\text { is better) }\end{array}$ & -144 (-724 to 406$)$ & $6.9^{*}(1.3$ to 12.6$)$ & -21 Dominant & 30.3 & 69.3 & 0.2 & 0.3 \\
\hline & 179 & 309 & QALYs (range: $0-1$ ) & -152 (-731 to 398$)$ & 0.040 (0.007 to 0.074$)$ & -3773 Dominant & 29.2 & 70.1 & 0.3 & 0.5 \\
\hline \multirow[t]{2}{*}{$\begin{array}{l}\text { SA6 -including } \\
\text { learning curve patients }\end{array}$} & 304 & 309 & $\begin{array}{l}\text { Leg pain (range: } 0-100 \text {, lower } \\
\text { is better) }\end{array}$ & $-2573(-3995$ to -1192$)$ & $5.4(0.7$ to 10.1$)$ & -476 Dominant & 0 & 98.9 & 1 & 0 \\
\hline & 304 & 309 & QALYs (range: $0-1$ ) & $-2602(-4028$ to -1226$)$ & 0.040 (0.012 to 0.068$)$ & -65097 Dominant & 0.0 & 99.7 & 0.3 & 0 \\
\hline
\end{tabular}

Please note that the difference in total societal costs of this table slightly differs from that of table 2 . This is given by the fact that in the current table, a system of seemingly unrelated regressions was used for estimating cost differences, whereas linear regression was used for table 2 .

*The difference measures improvement in leg pain symptoms; that is, positive number signalises a decrease in symptoms.

tVariable indicating preference for treatment was left out because it was constant in some of the bootstrapped samples.

ICER, incremental cost-effectiveness ratios; NE, north east; NW, north west; PTED, percutaneous transforaminal endoscopic discectomy; QALYs, quality-adjusted life years; SE, south east; SW, south west. 

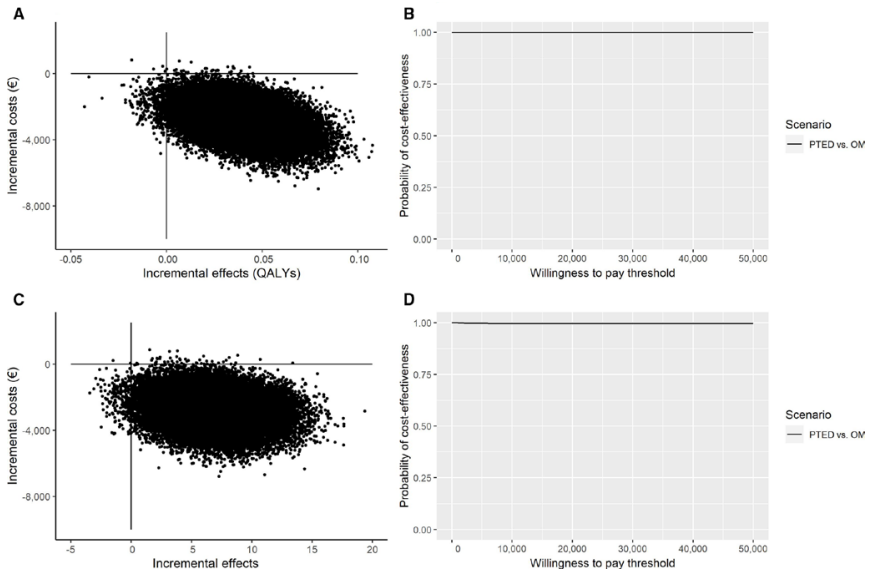

Figure 2 Cost-effectiveness plane for leg pain. PTED, percutaneous transforaminal endoscopic discectomy; QALYs, quality-adjusted life years.

of the study by the researchers, the participating clinics, the Dutch spine patient association, the Dutch association of orthopaedic surgeons, the Dutch association of neurosurgeons, and the Dutch spine society. Among others, the covenant included commitment to conduct the study as described in the study protocol, and to monitoring, communication and implementation. The main limitation of the study was that we did not succeed in recruiting the desired number of 682 patients (382 without learning curve). Recruitment was slower than expected, mainly because only four of the six clinics that had expressed an intention to participate included patients for this trial. Furthermore, some potential participants decided to undergo PTED in a private clinic at their own cost, because they did not accept the $50 \%$ chance of getting randomised to open microdiscectomy. However, the final number of 179 (instead of 191) participants randomised to PTED seems sufficient for a precise estimate of the difference in effect between PTED and open microdiscectomy, which is underscored by the relatively narrow confidence intervals around the cost and effect estimates. Furthermore, the sensitivity analysis that included the patients of the learning curve (total 304 patients in the PTED group) did not alter the results. Another limitation is the follow-up period of 12 months. Even though this is customary in trials investigating surgery for sciatica, long-term follow-up of the PTED-study may clarify long-term CE.

\section{Implications}

The findings of the PTED study are expected to have implications, both for patients at an individual level as for society. At an individual level, it has been shown that PTED is non-inferior to open microdiscectomy in the treatment of leg pain and that PTED has more favourable patient-reported outcomes such as less low back pain, less functional disability due to low back pain and a higher health-related quality of life at 12 months after surgery. ${ }^{21}$ These differences in outcomes between PTED and open microdiscectomy, however, were relatively small. Nonetheless, PTED requires no general anaesthesia, is performed as an outpatient procedure, has less intraoperative blood loss, leaves a smaller scar and does not require the back muscles to be removed from their insertion during surgery. By inducing less surgical trauma to the lumbar spine, PTED facilitates patients to mobilise earlier but also to return earlier to daily activities such as sport and work. The earlier resumption of daily activities is underlined by current finding that absenteeism, presenteeism, and unpaid productivity costs were lower among patients receiving PTED compared with those receiving open microdiscectomy. These findings warrant implementation of PTED as a treatment alternative to treat sciatica, not only for older patients who may be less suitable for receiving general anaesthesia, but also for younger active patients.

Aside from these clinical implications, there are also financial implications. When the PTED-study started, open microdiscectomy was included in the Dutch basic health insurance package and consequently reimbursed for all patients, but PTED was not. The Dutch Ministry of Health had classified PTED as an important, new and experimental technique to examine and decided that PTED would be conditionally admitted to the Dutch basic health insurance package for patients participating in this study. Based on the results, the Dutch Ministry of Health made the decision to include PTED in the basic health insurance package with a reimbursement rate similar to open microdiscectomy. As the actual reimbursement rate in the Netherlands is lower than the rate calculated in the primary analysis of this study, and as the healthcare market process will possibly lead to PTED becoming cheaper as it will be performed more frequently, it is to be expected that PTED will even be more likely to be costeffective than the primary analysis suggests.

Even though PTED is now reimbursed in the Netherlands, internationally, multiple health insurances still don't reimburse endoscopic techniques with the argument that these techniques have not been proven effective and should be considered experimental. This study suggests that this argument might need to be reconsidered. Challenges for the implementation of PTED are to ensure that it will be used for the right indication and that spine surgeons that are willing to start using PTED, get an adequate training and that the patients' safety is ensured during the learning curve by close monitoring of the results.

\section{CONCLUSION}

Results suggest that PTED is less costly and more effective and therefore cost-effective compared with open microdiscectomy for patients with lumbar disc herniation from the societal perspective. Therefore, PTED deserves to be included in the treatment armamentarium of sciatica.

\section{Author affiliations}

${ }^{1}$ Department of Neurological Surgery, Weill Cornell Brain and Spine Center, New York-Presbyterian/Weil Cornell Medicine New York, New York, USA

${ }^{2}$ Department of Neurosurgery, Erasmus MC, Rotterdam, The Netherlands

\section{Key messages}

What are the findings?

- Percutaneous transforaminal endoscopic discectomy (PTED) provides a larger reduction of leg pain, a larger increase in quality-adjusted life years (QALYs) and lower total costs than open microdiscectomy at 1-year follow-up.

- From the societal perspective, the probability of PTED being dominant compared to open microdiscectomy was $99.4 \%$ for leg pain and $99.2 \%$ for QALYs.

How might it impact on clinical practice in the future?

- The study results show that PTED is cost-effective in the treatment of sciatica compared to open microdiscectomy. Therefore, implementation as a treatment alternative to treat sciatica is warranted. 
${ }^{3}$ Department of Health Sciences, Faculty of Science, Amsterdam Public Health Research Institute, Vrije Universiteit Amsterdam, Amsterdam, The Netherlands ${ }^{4}$ Faculty of Behavioural and Movement Sciences, Amsterdam Movement Sciences research institute, Vrije Universiteit Amsterdam, Amsterdam, The Netherlands ${ }^{5}$ Department of Neurosurgery, Elisabeth-TweeSteden Ziekenhuis, Tilburg, The Netherlands

${ }^{6}$ Department of Neurosurgery, Leiden University Medical Center, Leiden, The Netherlands

${ }^{7}$ Department of Orthopedic Surgery, Rijnstate, Arnhem, The Netherlands ${ }^{8}$ Department of Physiotherapy \& Occupational Therapy, Aarhus University Hospital, Aarhus, Denmark

Acknowledgements We gratefully acknowledge the support of the Dutch Health Insurance Board, ZonMw, the participating patients, the patient organisation 'de Wervelkolom (nvvr)', dr. Pieter J. Schutte (Alrijne Hospital) and dr. Arnold Vreeling (Rijnstate Hospital) as study surgeons, and the research nurses Ms. Esther Willemsen, Ms. Steffi van Beek, Ms. Chantal Ritskes, Ms. Monique Stuit (Park MC), Ms. Paula van Limpt (Elisabeth-TweeSteden Hospital), Ms. Moniek Vroemen, Annemiek Hol (Rijnstate Hospital), and Marjon Nuijten (Alrijne Hospital).

Collaborators PTED-study group: Pieter I Schutte Arnold Vreeling.

Contributors PG, SR, MdB, MvT, JvS, WP and BH conceived the study, designed the trial and obtained grant funding. PG initiated the trial under supervision of SR and BH. PG, SR and BH managed the trial. PG acquired the data with the help of the research nurses. AS was partly involved in the trial management and data acquirement. BH trained the learning curve surgeons. BH, JvS, PD were three of the trial surgeons. PG and HB did the statistical analysis. HB coducted the economic evaluation under supervision of JVD. PG and HB wrote the first draft. All authors were responsible for the interpretation of the data and for reviewing and approving the final submitted manuscript. BH is the guarantor and accepts full responsibility for the work and the conduct of the study, had access to the data, and controlled the decision to publish. The corresponding author attests that all listed authors meet authorship criteria and that no others meeting the criteria have been omitted.

Funding This study was funded by ZonMw, The Netherlands Organisation for Health Research and Development (project number 837004013).

Competing interests None declared.

Patient consent for publication Not applicable.

Ethics approval Approval was granted by the Medical Ethical Committee of the VU Medical Centre Amsterdam (NL50951.029.14).

Provenance and peer review Not commissioned; externally peer reviewed.

Data availability statement Data are available on reasonable request.

Supplemental material This content has been supplied by the author(s). It has not been vetted by BMJ Publishing Group Limited (BMJ) and may not have been peer-reviewed. Any opinions or recommendations discussed are solely those of the author(s) and are not endorsed by BMJ. BMJ disclaims all liability and responsibility arising from any reliance placed on the content. Where the content includes any translated material, BMJ does not warrant the accuracy and reliability of the translations (including but not limited to local regulations, clinical guidelines, terminology, drug names and drug dosages), and is not responsible for any error and/or omissions arising from translation and adaptation or otherwise.

Open access This is an open access article distributed in accordance with the Creative Commons Attribution Non Commercial (CC BY-NC 4.0) license, which permits others to distribute, remix, adapt, build upon this work non-commercially, and license their derivative works on different terms, provided the original work is properly cited, appropriate credit is given, any changes made indicated, and the use is non-commercial. See: http://creativecommons.org/licenses/by-nc/4.0/.

ORCID iD

Pravesh Shankar Gadjradj http://orcid.org/0000-0001-9672-4238

\section{REFERENCES}

1 Konstantinou K, Dunn KM. Sciatica: review of epidemiological studies and prevalence estimates. Spine 2008;33:2464-72.

2 Ropper AH, Zafonte RD. Sciatica. N Engl J Med Overseas Ed 2015;372:1240-8.

3 Maslak JP, Jenkins TJ, Weiner JA, et al. Burden of sciatica on us Medicare recipients. J Am Acad Orthop Surg 2020;28:e433-9.
4 Fryhofer GW, Smith HE. Return to play for cervical and lumbar spine conditions. Clin Sports Med 2021;40:555-69.

5 van Tulder MW, Koes BW, Bouter LM. A cost-of-illness study of back pain in the Netherlands. Pain 1995;62:233-40.

6 Jensen RK, Kongsted A, Kjaer P, et al. Diagnosis and treatment of sciatica. BMJ 2019:359:16273

7 Gadjradj PS, Arts MP, van Tulder MW, et al. Management of symptomatic lumbar disk herniation: an international perspective. Spine 2017;42:1826-34.

8 Cherkin DC, Deyo RA, Loeser JD, et al. An international comparison of back surgery rates. Spine 1994;19:1201-6.

9 Yasargil MG. Microsurgical operation of herniated Lumbar-Disk. Acta Neurochir 1977;36:274-5.

10 Caspar W. New operative procedure of Lumbar-Disk herniation using a microscopic approach thereby causing less tissue injury. Acta Neurochir 1977;36:273-4.

11 Gadjradj PS, Harhangi BS. Percutaneous Transforaminal endoscopic discectomy for lumbar disk herniation. Clin Spine Surg 2016;29:368-71.

12 Kambin P, Sampson S. Posterolateral percutaneous suction-excision of herniated lumbar intervertebral discs. Report of interim results. Clin Orthop Relat Res 1986;207:37-43

13 Gadjradj PS, van Tulder MW, Dirven CMF, et al. Clinical outcomes after percutaneous transforaminal endoscopic discectomy for lumbar disc herniation: a prospective case series. Neurosurg Focus 2016;40:E3.

14 Wang $\mathrm{H}$, Huang $\mathrm{B}$, Li C, et al. Learning curve for percutaneous endoscopic lumbar discectomy depending on the surgeon's training level of minimally invasive spine surgery. Clin Neurol Neurosurg 2013;115:1987-91.

15 Barber SM, Nakhla J, Konakondla S, et al. Outcomes of endoscopic discectomy compared with open microdiscectomy and tubular microdiscectomy for lumbar disc herniations: a meta-analysis. J Neurosurg Spine 2019:802-15.

16 Kamper SJ, Ostelo RWJG, Rubinstein SM, et al. Minimally invasive surgery for lumbar disc herniation: a systematic review and meta-analysis. Eur Spine J 2014;23:1021-43.

17 Gadjradj PS, Harhangi BS, Amelink J, et al. Percutaneous Transforaminal endoscopic discectomy versus open Microdiscectomy for lumbar disc herniation: a systematic review and meta-analysis. Spine 2021;46:538-49.

18 Pan Z, Ha Y, Yi S, et al. Efficacy of Transforaminal endoscopic spine system (TESSYS) technique in treating lumbar disc herniation. Med Sci Monit 2016;22:530-9.

19 Krappel F, Schmitz R, Bauer E. Open or endoscopic nucleotomy? Orthopadische Praxis 2001:37:164-9.

20 Seiger A, Gadjradj PS, Harhangi BS, et al. PTED study: design of a non-inferiority, randomised controlled trial to compare the effectiveness and cost-effectiveness of percutaneous transforaminal endoscopic discectomy (PTED) versus open microdiscectomy for patients with a symptomatic lumbar disc herniation. BMJ Open 2017;7:e018230.

21 Gadjradj PS, Rubinstein SM, van Tulder MW, et al. Full-endoscopic versus open discectomy for sciatica: a randomized controlled non-inferiority trial. BMJ 2022.

22 Herdman M, Gudex C, Lloyd A, et al. Development and preliminary testing of the new five-level version of EQ-5D (EQ-5D-5L). Qual Life Res 2011:20:1727-36.

23 Drummond MF, Sculpher MJ, Claxton K. Methods for the economic evaluation of health care programmes. 4th ed. Oxford: Oxford university press, 2015.

24 Hakkaart-Van Roijen L, van der Linden N, Bouwmans C. Dutch costing manual: methodology for costing studies and reference prices for economic evaluations in health care 2016.

25 van Hooff ML, van Loon J, van Limbeek J, et al. The Nijmegen decision tool for chronic low back pain. development of a clinical decision tool for secondary or tertiary spine care specialists. PLoS One 2014;9:e104226.

26 Terluin B, van Marwijk HWJ, Adèr HJ, et al. The four-dimensional symptom questionnaire (4DSQ): a validation study of a multidimensional self-report questionnaire to assess distress, depression, anxiety and somatization. BMC Psychiatry 2006;6:34

27 White IR, Royston P, Wood AM. Multiple imputation using chained equations: issues and guidance for practice. Stat Med 2011;30:377-99.

28 Faria R, Gomes M, Epstein D, et al. A guide to handling missing data in cost-effectiveness analysis conducted within randomised controlled trials. Pharmacoeconomics 2014;32:1157-70.

29 Willan AR, Briggs AH, Hoch JS. Regression methods for covariate adjustment and subgroup analysis for non-censored cost-effectiveness data. Health Econ 2004;13:461-75

30 Fenwick E, O'Brien BJ, Briggs A. Cost-effectiveness acceptability curves--facts, fallacies and frequently asked questions. Health Econ 2004:13:405-15.

31 Black WC. The Ce plane: a graphic representation of cost-effectiveness. Med Decis Making 1990;10:212-4.

32 Choi K-C, Shim H-K, Kim J-S, et al. Cost-Effectiveness of microdiscectomy versus endoscopic discectomy for lumbar disc herniation. Spine J 2019;19:1162-9. 